\title{
Is There any Association Between CagA+ H. Pylori Infection and Histopathological Types of Gastric Carcinoma
}

\author{
Hassan MA ${ }^{1}$, Ahad MA², Rahman $\mathrm{MH}^{3}$, Bhuiyan $\mathrm{MSH}^{4}$, Khan MAH${ }^{5}$
}

\begin{abstract}
Enormous studies have been conducted worldwide regarding CagA+ status of $H$. pylori in gastric carcinoma. But no study relating CagA+ status and gastric carcinoma has been carried out in our country yet. Thus, this study has been designed to see the association between $\mathrm{CagA}+\mathrm{H}$. Pylori infection and histopathological types of gastric carcinoma. For this purpose, a total number of 80 (eighty) patients were selected. Of the 80 (eighty) patients 40 (forty) were selected as cases (malignant) and the remainder 40 (forty) were selected as controls (non-malignant). H. pylori was detected by applying non-invasive (H. pylori $\operatorname{Ig} G$ serology and CagA IgG serology) and invasive (Histology and rapid urease test) technique. Of them Histology was done by Modified giemsa stain which was regarded as gold standard, CagA IgG was detected by ELISA method. Study reveals that there is no significant difference between histologic sub-types (Intestinal vs. Diffuse) of gastric carcinoma in relation with $H$. pylori positivity and present study also shows that there is no significant difference among the sites of lesion regarding $H$. pylori positivity. In this study, we see that among the 40 cases, 35(thirty five) possess the CagA+ H. pylori strain. And among the 40 controls, 33(thirty three) bear the CagA+H. pylori strain. Here case-control difference is insignificant regarding CagA $\operatorname{IgG}$ status.The present study supports the view of an association of $H$. pylori infection with both intestinal and diffuse types of gastric cancer. It may be possible that $H$. pylori may be causally related to both forms of gastric
\end{abstract}

\footnotetext{
1. Md. Ali Hassan,

Lecturer, Dept. Of Pathology, Khulna Medical College, Khulna.

2. Md. Abdul Ahad,

Associate Professor,Dept. of Gastroenterology, Khulna Medical

College, Khulna.

3. Md. Habibur Rahman,

Professor of Gastroenterology, M A G Osmani Medical College,

Sylhet.

4. Md. Sohorab Hossain Bhuiyan,

Associate Professor, Department of Pathology, JRRMC, Sylhet.

5. Md. Amjad Hossain Khan,

Professor, Department of Pathology, MAG Osmani Medical

College, Sylhet.
}

cancer via unknown mechanism or this finding may be due to small sample size. In this study, no significant difference between case and control on the point of CagA IgG status was found. There are sufficient papers in favor of it-which argues that CagA positivity as well as $H$. pylori positivity is not the sole causative agent of gastric carcinoma. If so,it merely acts as an initiator.However,it is being left open for the future researchers to prove or to disprove it

\section{Introduction:}

Stomach cancer has been recognized for several millennia ${ }^{1}$ and worldwide, however, it is the second leading cause of cancer related death ${ }^{2}$. In the early 1970 s, Correa formulated a multi-step model of gastric cancer, which postulated a temporal sequence of pathologic changes that led from chronic (Type-B) gastritis to atrophic gastritis, intestinal metaplasia, and dysplasia and the eventual development of gastric cancer ${ }^{3}$. Our understanding of gastric cancer underwent a marked shift with the re-discovery of Helicobacter pylori ${ }^{1}$. In the late1970s Warren also noted the bacteria, and in 1982 Barry Marshall and Robin Warren were able to culture the organism and proved the association with gastritis and peptic ulcer disease ${ }^{4}$. It was recognized as a separate genus and renamed "Helicobacter pylori" in $1989^{1}$. Self-ingestion experiments by Marshall ${ }^{5}$ and Morris ${ }^{6}$ and later experiments with volunteers ${ }^{7}$ demonstrated that this bacteria can colonize the human stomach, thereby inducing inflammation of the gastric mucosa. Further studies suggested that gastric colonization with $\mathrm{H}$. pylori can lead to a variety of upper gastrointestinal disorders, such as chronic gastritis, peptic ulcer disease, gastric mucosa associated lymphoid tissue lymphoma (MALT lymphoma), and gastric cancer. Robin Warren and Barry Marshall were awarded Nobel Prize 2005 in Physiology or Medicine for their "discovery of the bacterium Helicobacter pylori and its role in gastritis and peptic ulcer disease." 8

A causal relationship between Helicobacter pylori and gastric cancer was first postulated by Marshall and Warren 
in $1983^{8}$. H. pylori is the first bacterium identified as being carcinogenic in humans ${ }^{9}$. The association between gastric adenocarcinoma and $\mathrm{H}$. pylori was confirmed by many subsequent investigations, leading to the consensus that the bacterium is a class 1 carcinogen ${ }^{9}$. Helicobacter infection is the leading cause of gastric cancer worldwide ${ }^{3}$. There is increasing evidence that persistent infection with Helicobacter pylori is a risk factor for gastric adenocarcinoma $^{10-11}$ especially of the distal stomach ${ }^{12}$. The evidence comes mainly from epidemiological investigations ${ }^{13-14}$ including nested case control studies ${ }^{15-16}$ and molecular and pathological studies support its biological plausibility ${ }^{17}$. However, although H. pylori infection is highly prevalent in patients with gastric cancer, most H. pylori infected persons never develop these neoplasms ${ }^{18}$. A logical next step is to identify other factors that more precisely determine risk among $\mathrm{H}$. pylori infected persons. H. pylori strains are highly diverse ${ }^{19}$. and individuals may harbour more than one strain ${ }^{20}$.

Helicobacter pylori is not a clonal organism and exhibits great genetic diversity ${ }^{21-22}$. At the phenotypic level, strains can be characterized into two types: those that contain a gene associated with cytotoxin expression, the so called CagA gene, and those that do not ${ }^{23}$. However, approximately $60 \%$ of isolates possess a gene, cagA, which encodes a high molecular weight protein $(\mathrm{CagA})$ of variable size (M 1,20,000-1,40,000) ${ }^{24-25}$. Studies suggest that persons infected with $\mathrm{CagA}+$ strains have higher degrees of gastric inflammation and epithelial cell damage than do persons from whom CagA- strains have been isolated ${ }^{26}$. Persons infected with $\mathrm{CagA}+\mathrm{H}$. pylori strains have enhanced expression of IL-1a, IL-b \& IL-8 in gastric biopsies compared to uninfected persons or patients infected with CagA- strains ${ }^{27}$. Since both intensity of inflammation and epithelial damage may be involved in pathogenesis of gastric cancer ${ }^{10}$ it is reasonable to examine the importance of CagA in this context. In one study Parsonnet and colleagues (1997) ${ }^{28}$ stated that subjects infected with $\mathrm{H}$. pylori who had CagA antibodies were 5.8- fold more likely than uninfected subjects to develop gastric cancer. In our country study had been carried out showing relation of $\mathrm{H}$. pylori with gastric malignancy but to the best of my knowledge no study relating $\mathrm{CagA}+$ status with gastric carcinoma has been carried out yet. Therefore, this study has been designed to see the association between $\mathrm{CagA}+\mathrm{H}$. Pylori infection and histopathological types of gastric carcinoma.

\section{MATERIALS AND METHOD}

This prospective randomized case control study was carried out in the Department of Pathology, Sylhet M A G Osmani
Medical College, during the period of January 2008 to December 2008.

\section{Study Population}

Patients and control subjects were selected consecutively from endoscopic unit of Dept. of Gastroenterology of Sylhet M A G Osmani medical College and a private practice in Sylhet city.The clinical history of the patients were noted. The patients were examined thoroughly.History; physical finding and reports of investigations were recorded in a form prepared for this purpose. Patients having clinical features suggestive of carcinoma stomach were selected for upper GI endoscopy. The endoscopic examinations were performed by experienced endoscopists using video endoscope and biopsies were taken from the lesions suspicious of malignancy for histopathology. When histopathology was found compatible with gastric carcinoma, the subject was selected as case. In order to detect $H$. pylori, tissue were taken from non- involved area of antrum and fundus of stomach for histopathological examination and rapid urease test.

Subjects with normal upper GI endoscopy and histopathologically proved non-malignant were taken as controls and 40 (forty) persons were taken consecutively. Tissue biopsies were taken from the antrum and fundus for rapid urease test and histologic diagnosis of $\mathrm{H}$. pylori from the control. 3 (three) to 4 (four) cc blood was aspirated from each case as well as control for serology. Rapid urease test was done by inoculating endoscopic biopsy material in Christensen's urea agar and urea solution. Serology was done to detect $\mathrm{H}$. pylori $\operatorname{IgG}$ antibody and CagA IgG antibody by ELISA method.

\section{Inclusion Criteria}

All the patients clinically suspected of gastric malignancy and confirmed by histopathology 15 years and above.

\section{Exclusion Criteria}

1.Patients refuse endoscopy 2.Failed endoscopy. 3.Diagnosis of carcinoma not proved histopathologically. 4.Taking H. pylori eradication therapy within last four weeks of endoscopy 5. Major organ failure. 6.Pregnant women.

\section{The following outcome variables were studied}

Primarily $\mathrm{CagA}+$ status in gastric carcinoma patients with histopathological report. Secondarily site of lesion, economic status and smoking habit.

\section{RESULTS AND OBSERVATION}

A total of 48 patients of suspected gastric malignancy attending the gastroenterology department of Sylhet MAG Osmani medical college and a private practice in the Sylhet city was included in this study. 
Age distribution of the patients:

Table-1. Distribution of study subjects on the basis of age

\begin{tabular}{|c|c|c|c|c|}
\hline \multirow{2}{*}{$\begin{array}{c}\text { Age group of Patients } \\
\text { (Years) }\end{array}$} & \multicolumn{3}{|c|}{ Sex of the Patient } \\
\cline { 2 - 5 } & \multicolumn{2}{|c|}{ Male } & 5 & $16.1 \%$ \\
\hline $21-30$ & 9 & $18.4 \%$ & 3 & $9.7 \%$ \\
\hline $31-40$ & 5 & $10.2 \%$ & 10 & $32.3 \%$ \\
\hline $41-50$ & 8 & $16.3 \%$ & 9 & $29.0 \%$ \\
\hline $51-60$ & 12 & $24.5 \%$ & 2 & $6.5 \%$ \\
\hline $61-70$ & 8 & $16.3 \%$ & 0 & 00 \\
\hline $71-80$ & 6 & $12.2 \%$ & 2 & $6.5 \%$ \\
\hline $81-90$ & 1 & $2.0 \%$ & & 2 \\
\hline
\end{tabular}

The age range of total 80 patients was between 21 and 90 years with the mean age of 51.89 with std. deviation \pm 16.93 . The highest number of subjects (21 in number) were seen in 6th decade.

Table-2. Distribution of study subjects on the basis of sex.

\begin{tabular}{|c|c|c|c|c|c|c|c|c|c|}
\hline \multirow{3}{*}{$\begin{array}{c}\begin{array}{c}\text { Age group of } \\
\text { Patients (Years) }\end{array} \\
21-30 \\
\end{array}$} & \multicolumn{4}{|c|}{ Sex of the Patient (Case) } & \multicolumn{4}{|c|}{ Sex of the Patient (Control) } & \multirow[t]{3}{*}{ M:F } \\
\hline & \multicolumn{2}{|c|}{ Male } & \multicolumn{2}{|c|}{ Female } & \multicolumn{2}{|c|}{ Male } & \multicolumn{2}{|c|}{ Female } & \\
\hline & 0 & 0 & 1 & $6.3 \%$ & 9 & $36.0 \%$ & 4 & $26.7 \%$ & \\
\hline $31-40$ & 1 & $4.2 \%$ & 1 & $6.3 \%$ & 4 & $16.0 \%$ & 2 & $13.3 \%$ & \\
\hline $41-50$ & 3 & $12.5 \%$ & 7 & $43.8 \%$ & 5 & $20.0 \%$ & 3 & $20.0 \%$ & \\
\hline $51-60$ & 10 & $41.7 \%$ & 6 & $37.5 \%$ & 2 & $\$ .0 \%$ & 3 & $20.0 \%$ & $1 . \$ 8.1$ \\
\hline $61-70$ & 5 & $20.8 \%$ & 1 & $6.3 \%$ & 3 & $12.0 \%$ & 1 & $6.7 \%$ & \\
\hline $71-80$ & 4 & $16.7 \%$ & 0 & 0 & 2 & $\$ .0 \%$ & 0 & 0 & \\
\hline $81-90$ & 1 & $4.2 \%$ & 0 & 0 & 0 & 0 & 2 & $13.3 \%$ & \\
\hline
\end{tabular}

Total number of male and female in the case is 24 and 16 respectively with mean age 57.73 and std. deviation \pm 12.21 . Total number of male and female in control is 25 and 15 respectively. The number of males was 49 and the number of females was 31. The overall Male: Female ratio was 1.58:1.

Table-3. Frequency table of the habit of patients (case)

\begin{tabular}{|l|c|c|}
\hline \multicolumn{1}{|c|}{ Habit } & Frequency & Percent \\
\hline None & 3 & 7.5 \\
\hline Smoker & 10 & 25.0 \\
\hline Betel leaf and betel nut & 16 & 40.0 \\
\hline Cigarette, betel leaf \& betel nut & 11 & 27.5 \\
\hline Total & $\mathbf{4 0}$ & $\mathbf{1 0 0 . 0}$ \\
\hline
\end{tabular}

Those who are habituated with betel leaf $\&$ betel nut ranking the highest (16 in number). 
Table-4. Findings of various diagnostic procedures.

\begin{tabular}{|c|c|c|c|c|c|c|c|c|c|c|c|c|}
\hline \multirow[b]{2}{*}{$\begin{array}{l}\text { Patients } \\
\text { group }\end{array}$} & \multicolumn{4}{|c|}{ Rapid Urease test for $H$. pylori } & \multicolumn{4}{|c|}{ Findings of Modified Giemsa Stain } & \multicolumn{2}{|c|}{$\begin{array}{l}\text { H. pylori } \\
\text { IgG } \\
\text { status }\end{array}$} & \multicolumn{2}{|c|}{$\begin{array}{l}\text { CagA } \\
\text { IgG } \\
\text { status }\end{array}$} \\
\hline & 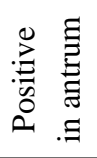 & 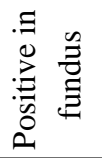 & 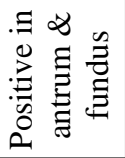 & 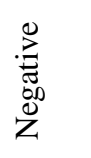 & 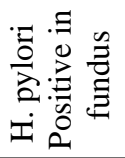 & 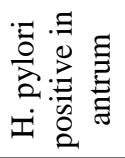 & 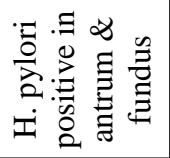 & 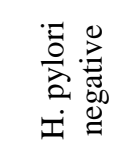 & & & : & 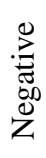 \\
\hline Case & 7 & 7 & 10 & 16 & 6 & 9 & 11 & 14 & 40 & 35 & 5 & \\
\hline Control & 10 & 4 & 6 & 20 & 9 & 6 & 2 & 23 & 40 & 33 & 7 & \\
\hline
\end{tabular}

Table shows all the study subjects are H. pylori IgG positive.

Table-5. Male Female distribution of histologic sub-types of gastric carcinoma.

\begin{tabular}{|l|c|c|c|c|}
\hline \multirow{2}{*}{ Histologic Sub Type } & \multicolumn{3}{|c|}{ Sex of the Patient } \\
\cline { 2 - 5 } & \multicolumn{2}{|c|}{ Male } & \multicolumn{2}{c|}{ Female } \\
\hline Adenocarcinoma, intestinal type & 22 & $44.9 \%$ & 13 & $41.9 \%$ \\
\hline Adenocarcinoma, diffuse type & 2 & $4.1 \%$ & 3 & $9.7 \%$ \\
\hline
\end{tabular}

Here, intestinal variant occurs twice as common in males than in females (22:13) and diffuse variant is distributed almost equally in between them.

Table-6. Case-Control association in relation with CagA IgG status.

\begin{tabular}{|l|c|c|c|c|c|}
\hline \multirow{2}{*}{ CagA IgG status } & \multicolumn{4}{|c|}{ Patients group } & \multirow{2}{*}{$\mathbf{X}^{\mathbf{2}}$} \\
\cline { 2 - 5 } & \multicolumn{2}{|c|}{ Case } & 33 & $82.5 \%$ & \multirow{2}{*}{ Control } \\
\cline { 2 - 5 } Positive & 35 & $87.5 \%$ & 7 & $17.5 \%$ & $p=1.00$ \\
\hline Negative & 5 & $12.5 \%$ & & & \\
\hline
\end{tabular}

Statistics reveals that there is no significant difference between case and control (chi-square test; $p=1.00$ )

\section{DISCUSSION}

Before the association between Helicobacter pylori and gastric cancer was brought attention of the medical community, the pathology of the neoplasia and its precancerous lesions was well established (Correa and Houghton 2007) ${ }^{3}$. Gastric cancer has been recognized for several millennia. But people were not aware of the exact causative agent of this deadly disease. Discovery of the organism H. pylori by Warren and Marshall in $1982^{5}$ and claiming the organism as the causative agent of gastric carcinogenesis in 1983 (Marshall and Warren, 1984) ${ }^{8}$ had cast dim light on it for the first time.Enormous research works had been carried out since then from every corner of the world in order to get valid information about this organism as well as its role as the causative agent of this disease. The historical award winning lecture, delivered by Correa has focused great beam of light about the causation of this fatality (Correa 1992) ${ }^{17}$. Correa postulated that Gastric cancer is the end result of a sequential multistep and multifactorial process (chronic gastritis; atrophy; intestinal metaplasia; and dysplasia); where H. pylori and excessive salt intake was detected as the prime initiator. He has orchestrated with the findings of Warren and Marshall.

Correa's postulates were supported by many investigators later on. Prospective serologic studies have reported that persons with $\mathrm{H}$. pylori infection have a three-to six fold higher risk of gastric cancer (Nomura et al.1991; Parsonnet et al.1991; Forman et al.1991) $)^{15,16,29}$. Another citation by 
Talukder and colleagues (1996) ${ }^{31}$ in Bangladesh is that there is significant association found between $\mathrm{H}$. pylori and both intestinal and diffuse types of gastric cancer. In the article "Pathogenesis of Helicobacter pylori Infection", Kusters and associates (2006) depicted that $\mathrm{H}$. pylori colonization increases the risk of gastric cancer approximately 10-fold. and $\mathrm{H}$. pylori was designated a class I carcinogen by the WHO (IARC 1994) ${ }^{9}$. Helicobacter is the leading cause of gastric cancer worldwide (Correa and Houghton 2007) 3 . However, although $\mathrm{H}$. pylori infection is highly prevalent in patients with gastric cancer, but many of the $\mathrm{H}$. pylori infected persons never develop these neoplasms (Taylor and Blaser 1991) ${ }^{18}$. Certainly there is some fallacy. To answer to this fallacy, it is to be said that there are other factors of which the most important one is the diversity of strains of H. pylori. At the phenotypic level, H. pylori strains can be characterized into two types: those that contain a gene associated with cytotoxin expression, the so called cagA gene, and those that do not (Telford et al. 1994) ${ }^{23}$. Studies of gastric carcinoma relating $H$. pylori infection had been carried out in our country. But no study relating gastric carcinoma with $\mathrm{CagA}+$ status has been carried out yet. So, this study had been planned to see the association between socio-demographic determinants and gastric carcinoma in $\mathrm{CagA}+\mathrm{H}$. pylori strains.

In this study, age range of total 80 patients (case and control) was between 21 and 90 years with the mean age of 51.89 with standard deviation 16.93 ( $\mathrm{SD} \pm 16.93)$. The highest number of subjects (21 in number) fall in the age group 51- 60 years (Table-1). The number of males was 49 and the number of females was 31 . The overall male: female ratio was 1.58: 1 (Table-2). Study also discloses that among cases, who were habituated with betel leaf and betel-nut ranking the highest (16 in number) (Table-3). Here, we see positivity of $\mathrm{H}$. pylori $\mathrm{IgG}$ antibody is $100 \%$ among study subjects (Table-4). This finding is consistent with the findings of others (Ahmad et al.2007; Talukder et al.1996; Taylor and Blaser1991; Terradot 2005) ${ }^{18,31}$. 1A study carried out in Sylhet MAG Osmani Medical College, with the undergraduate students shows that it was 92\%.In this study IGCA (Intestinal type gastric carcinoma) tends to occur twice as common in males than in females (Male: Female $=22: 13$ ). Whereas in case of DGCA (Diffuse type gastric carcinoma), males and females are near equal in number (2:3) (Table-5). Similar result were observed in other studies (Kumar et al. 2004; Fuchs and Mayer 1995).32 This study reveals no case-control differentiation regarding CagA IgG status(Table-6).

There are many studies, which reveal that there is association between gastric carcinoma and CagA positivity. Such as, findings observed by Asahi and associates $(2000)^{33}$, Segal (1999) $)^{34}$ and Atherton (1995) ${ }^{35}$. Study carried out by Kuipers and associates $(1995)^{36}$, Blaser and colleagues $(1995)^{37}$ also stated that patients with peptic ulceration, pre-neoplastic and neoplastic gastric epithelial lesions are more likely to be infected by $\mathrm{CagA}+$ strains. But there are controversial opinions also. Maeda and colleagues $(1998)^{38}$ and Yamaoka and associates $(2002)^{39}$ stated that since, the majority of $\mathrm{H}$. pylori infected individuals in Asian countries harbour cagA-positive strains, associations of cagA status and diseases are not observed in Asia. Study carried out in India by Kumar and colleagues (1998) $)^{40}$, showed that antibodies to CagA protein are not predictive of serious gastroduodenal disease. And this is contradictory to the studies from developed countries. Genotype analysis of H. pylori strains from India showed pathogenic strains to be present in more than $80 \%$ of adults and children with gastroduodenal diseases as well as control population (Singh et al. 2003) ${ }^{41}$. Studies that used CagA antibody in patients with non-ulcer dyspepsia have shown that CagA antibody is detected in sera of most patients (Kumar et al. $1998)^{40}$. Ghoshal and colleagues (Ghoshal et al.2005) ${ }^{42}$ stated that a large study, carried out in their centre showed that frequency of CagA IgG antibody was similar among the patients with gastric carcinoma and the controls, suggesting that difference in virulence factors of $\mathrm{H}$. pylori, at least CagA is unlikely to explain the variation in outcome of $\mathrm{H}$. pylori infection. Sing and Ghoshal $(2006)^{43}$ stated that $\mathrm{H}$. pylori alone is not the only independent factor in gastric carcinogenesis in India Several studies carried out by Satarkar and colleagues (1997) ${ }^{44}$, Prabhu and associates $(1995)^{45}$ and Subarna and Shashidharan $(1995)^{46}$ come to conclusion that intestinal metaplasia is rare following $\mathrm{H}$. pylori infection, and the organism may not be important in the development of gastric cancer in India. Studies from India failed to show an association between $\mathrm{H}$. pylori infection and gastric cancer (Kate and Anantakrishnan 2000; Kate et al.1998; Khanna et al.2002 $)^{47,48,49}$. However, these controversies merge with the ultimate finding of this study.

Enormous studies have been conducted worldwide regarding $\mathrm{Cag} \mathrm{A}+$ status of $\mathrm{H}$. pylori in gastric carcinoma. But no study relating $\mathrm{Cag} \mathrm{A}+$ status and gastric carcinoma has been carried out in our country yet. Thus, this study has been designed to see the association between $\mathrm{CagA}+\mathrm{H}$. Pylori infection and histopathological types of gastric carcinoma. For this purpose, a total number of 80 (eighty) patients were selected. Of the 80 (eighty) patients 40 (forty) were selected as cases (malignant) and the remainder 40 (forty) were selected as controls (non-malignant). H. pylori was detected by applying non-invasive (H. pylori IgG serology and CagA IgG serology) and invasive (Histology and rapid urease test) technique. Of them Histology was done by Modified giemsa stain which was regarded as gold standard, CagA IgG was detected by ELISA method.Study reveals that there is no significant difference between histologic sub-types (Intestinal vs. Diffuse) of gastric carcinoma in relation with $\mathrm{H}$. pylori positivity and present 
study also shows that there is no significant difference among the sites of lesion regarding $\mathrm{H}$. pylori positivity. In this study, we see that among the 40 cases, 35(thirty five) possess the CagA + H. pylori strain. And among the 40 controls, 33(thirty three) bear the CagA $+\mathrm{H}$. pylori strain. Here case-control difference is insignificant regarding CagA IgG status. The present study supports the view of an association of $\mathrm{H}$. pylori infection with both intestinal and diffuse types of gastric cancer. It may be possible that $\mathrm{H}$. pylori may be causally related to both forms of gastric cancer via unknown mechanism or this finding may be due to small sample size. In this study, no significant difference between case and control on the point of CagA IgG status was found. There are sufficient papers in favor of it-which argues that CagA positivity as well as $\mathrm{H}$. pylori positivity is not the sole causative agent of gastric carcinoma. If so,it merely acts as an initiator.However,it is being left open for the future researchers to prove or to disprove it.

\section{References:}

1. Houghton J, Wang TC. Helicobacter pylori and gastric cancer: A new paradigm for inflammation-associated epithelial cancers. Gastroenterology. 2005;128:1567-78.

2. Meimarakis G, Winter H, Assmann I. Helicobacter pylori as a prognostic indicator after curative resection of gastric carcinoma: a prospective study. Lancet Oncol. 2006;7:211-22.

3. Correa P, Houghton J.Carcinogenesis of Helicobacter pylori. Gastroenterology 2007;133: 659-72.

4. Marshall BJ, Armstrong JA, McGechie DB. Attempt to fulfill Koch's postulates for pyloric Campylobacter. Med J Austr. 1985;142:436-9.

5. Vilaichone RK, Mahachai V, Graham DY. Helicobacter pylori diagnosis and management. Gastroenterol Clin N Am. 2006;35: 229-47.

6. Morris A, and Nicholson G. Ingestion of Campylobacter pyloridis causes gastritis and raised fasting gastric $\mathrm{pH}$. Am J Gastroenterol. 1987; 82:192-9.

7. Morris AJ, Ali MR, Nicholson GI. Long-term followup of voluntary ingestion of Helicobacter pylori. Ann Intern Med. 1991;114:662-3.

8. Marshall BJ, Warren JR. Unidentified curved bacilli in the stomach of patients with gastritis and gastric ulceration. Lancet. 1984; 1:1311-5.

9. IARC 1994. Working Group on the Evaluation of Carcinogenic Risks to humans. Helicobacter pylori. In: Schistosomes, liver flukes, and Helicobacter pylori: view and expert opinions of an IARC Working group on the Evaluation of Carcinogenic Risks to Humans. Lyon: IARC. 1994;177-240.

10. Blaser MJ, and Parsonnet J. Parasitism by the "slow" bacterium Helicobacter pylori leads to altered gastric homeostasis and neoplasia. J Clin Invest. 1994;94.

11. Correa P. Is gastric carcinoma an infectious disease? $\mathrm{N}$ Engl J Med. 1991;325:1170-1.

12. Talley NJ, Zinsmeister AR, Dimagno EP.Gastric adenocarcinoma and Helicobacter pylori infection. J Natl Cancer Inst. 1991; 83:1734-9.

13. Asaka M, Kimura T, Kato M. Possible role of Helicobacter pylori infection in early gastric cancer development. Cancer (Phila.). 1994;73:2691-4.

14. Sipponen P, and Hyvarinen H. Role of Helicobacter pylori in the pathogenesis of gastritis, peptic ulcer and gastric cancer. Scand J Gastroentrol. 1993;196:S3-S6.

15. Parsonnet J, Friedman GD, Vandersteen DP. Helicobacter pylori infection and the risk of gastric carcinoma. N Engl J Med. 1991;325:1127-31.

16. Nomura A, Stemmermann GN, Chyou P. Helicobacter pylori infection and gastric carcinoma in population of Japanese-Americans in Hawaii. N Engl J Med. 1991; 325:1132-6.

17. Correa P. Human Gastric Carcinogenesis: A Multistep and Multifactorial Process-First American Cancer Society Award Lecture on Cancer Epidemiology and Prevention. Cancer Research.1992;52: 6735-40.

18. Taylor DN, and Blaser MJ.The epidemiology of Helicobacter pylori infections. Epidemiol Rev. 1991;13:42-59

19. Fujimoto S, Marshall B, and Blaser MJ. PCR-based restriction fragment length polymorphism typing of $\mathrm{H}$. pylori. J. Clin. Microbiol. 1994;32:331-4.

20. Prewett EJ, Bickley J, Owen RJ. DNA patterns of Helicobacter pylori isolated from gastric antrum, body and duodenum. Gastroenterology. 1992;102:829-33.

21. Cover TL,Tummuru MK,Cao P. Divergence of genetic sequences for the vacuolating cytotoxin among Helicobacter pylori strains. J Biol Chem.1994; 269:10566-73. 
22. Taylor DE, Eaton M, Chang N. Construction of a Helicobacter pylori genome map and demonstration of diversity at the genome level. J Bacteriol. 1992;174:6800- 06.

23. Telford JL, Covacci A, Ghiara P. Unravelling the pathogenic role of Helicobacter pylori in peptic ulcer: potential new therapies and vaccines. Trends Biotechnol. 1994;12:120-6.

24. Tummuru, MKR, Cover TL, and Blaser MJ. Cloning and expansion of a high molecular weight major antigen of Helicobacter pylori: evidence of linkage to cytotoxin production. Infect. Immunol. 1993; 61:17991809.

25. Covacci A, Censini S, Bugnoli M. Molecular characterization of the $128-\mathrm{kDa}$ immunodominant antigen of Helicobacter pylori associated with cytotoxicity and duodenal ulcer. Proc Natl Acad Sci USA. 1993;90:5791-5.

26. Crabtree JE,Taylor JD, Wyatt JI. Mucosal IgA detection of Helicobacter pylori $120 \mathrm{kDa}$ protein, peptic ulceration, and gastric pathology. Lancet.1991;338:3325 .

27. Peek RM, Miller GG, Tham KT. Detection of cagA expression in vivo and demonstration of preferential cytokine expression by cagA $+\mathrm{H}$. pylori strains in gastric mucosa.Am J Gastroenterol. 1994; 89:1344.

28. Parsonnet J, Friedman GD, Orentreich N. Risk for gastric cancer in people with CagA positive or CagA negative Helicobacter pylori infection. Gut.1997; 40: 297-301.

29. Forman D, Newell DG, Fullerton F, et al. Association between infection with Helicobacter pylori and risk of gastric cancer: evidence from a prospective investigation. Br. Med. J. 1991;302:1302-5.

30. Talukder MS, Khan BR, Islam B. Association of Helicobacter pylori (H. pylori) With Gastric cancer And Other Gastroduodenal Lesions. Bangladesh J Pathol. 1996;11:13-7.

31. Terradot L. Helicobacter pylori.European Synchroton Radiation Facility(ESRF). 2005:1-7.

32. Fusch CS. and Mayer RJ. Gastric Carcinoma. The New England Journal Of Medicine. 1995;333:32-41.

33. Asahi M, Azuma T, Ito S. Helicobacter pylori CagA protein can be tyrosine phosphorylated in gastric epithelial cells. J Exp Med. 2000;191:593-602.

34. Segal ED, Cha J, Lo J. Altered states: Involvement of phosphorylated CagA in the induction of host cellular growth changes by Helicobacter pylori. Proc Natl Accad Sci USA. 1999;96:14559-64.

35. Atherton JC, Cao P, Peek RM. Mosaicism in vacuolating cytotoxin alleles of Helicobacter pyloriassociation of specific vacA types with cytotoxin production and peptic ulceration. J Biol Chem. 1995;270:1771-7.

36. Kuipers EJ, Perez-Perez GI, Meuwissen SGM. Helicobacter pylori and atrophic gastritis: importance of the cagA status. J Natl Cancer Inst. 1995;87:1777-80.

37. Blaser MJ, Guillermo I, Perez-Perez. Infection with Helicobacter pylori strains possessing cagA is associated with an increased risk of developing adenocarcinoma of the stomach. Cancer research. 1995;55:2111-5.

38. Maeda S,Ogura K, Yoshida H. Major factors VacA and CagA, are commonly positive in Helicobacter isolates in Japan. Gut. 1998;42:338-43.

39. Yamaoka Y, Souchek J, Odenbreit S. Discrimination between cases of duodenal ulcer and gastritis on the basis of putative virulence factors of Helicobacter pylori. J Clin Microbiol. 2002;40:2244-6.

40. Kumar S, Dhar A, Srinivasan S. Antibodies to CagA protein are not predictive of serious gastroduodenal disease in Indian patients. Indian $\mathbf{J}$ Gastroenterol. 1998; 17:126-8.

41. Singh M, Prasad KN, Yaccha SK. Genotype of Helicobacter pylori in children with upper abdominal pain. J Gastroenterol Hepatol. 2003;18:1018-23.

42. Ghoshal UC, Tiwari S, Pandey R. Helicobacter pyloriinduced apoptosis in gastric carcinoma. Indian Journal of gastroenterology. 2005;24:193-6

43. Singh K,Ghoshal UC.Causal role of Helicobacter pylori infection in Gastric cancer: An Asian enigma. World J Gastrenterology. 2006;12:1346-91.

44. Satarkar RP, Sawant P, Nanivadekar S. Helicobacter pylori and intestinal metaplasia of gastric mucosa. Indian J Gastroenterol. 1997;16:18-9.

45. Prabhu SR, Amrapurkar AD, Amrapurkar DN. 1995. Role of Helicobacter pylori in gastric cancer. Natl Med J 
India. 8:58-60.

46. Subarna N, Shashidharan VP. Histopathological and histogenic study of carcinoma stomach in a high risk area. Indian J Cancer. 1995;32:36-42.

47. Kate V, Anantakrishnan N. Helicobacter pylori and gastric carcinoma: evidence for the link. Natl Med J India. 2000;13:329.
48. Kate V,Anantakrishnan N,Badrinath S. 1998. Prevalence of Helicobacter pylori infection in disorders of the upper gastrointestinal tract in South India. Natl Med J India.11:5-8.

49. Khanna AK, Seth P, Nath G. Correlation of Helicobacter pylori and gastric carcinoma. Postgrad Med J India. 2002;48:27-8. 